\title{
MORFODINÂMICA DAS DUNAS DO BAIRRO BOCA SUR, ZONA LITORÂNEA DA REGIÃO DO BIOBÍO, CHILE
}

\author{
Morphodynamics of dunes in the neighborhood Boca Sur, coastal zone of Biobío region, Chile
}

Tatiana Costa

Universidad de Concepción, Cocepción, Provincia de Concepción, Chile tati.ufsc@gmail.com

Leonel Perez

Universidad de Concepción, Cocepción, Provincia de Concepción, Chile leperez@udec.cl

Artigo recebido em 09/08/2013 e aceito para publicação em 15/05/2014.

RESUMO: O presente artigo apresenta o estudo da morfodinamica das dunas do bairro Boca Sur, área metropolitana de Concepción, Chile, com objetivo de levantar critérios de uso e ocupação da área na construção de um parque urbano. Foi realizada a caracterização do campo de dunas e área circundante, incluindo seus componentes ambientais e sociais. Para isso, foi utilizado como método observação de campo, estudos antecedentes da área, elaboração de perfis topográficos das dunas e análise comparativa das imagens de satélites dos anos de 1978 e 2011. Os resultados apontam para uma perda de território de praia e dunas da área litorânea do bairro Boca Sur devido a fatores naturais e antrópicos, ressaltando também os possíveis riscos naturais que sofre a área de construção do parque por sua localização, relevo e dinâmica de seus elementos naturais. Por meio de um microzoneamento, as conclusões estabelecem usos preferentes e restrições à ocupação do campo de dunas, desde o ponto de vista do uso sustentável, considerados relevantes para uma futura intervenção.

Palavras-chaves: morfodinamica de dunas, zona costeira, parque urbano, riscos naturais, Chile.

ABSTRACT This paper presents the study of the morphodynamics of dunes of Boca Sur neighborhood, located at the metropolitan region of Concepción, Chile. The purpose is to establish criteria to the use and occupation of the area for the construction of an urban park. A characterization of the dune's field and surrounding area were made, including its environmental and social components. The method used was field's observation, literature review, elaboration of dunes' topographic profile and comparative analysis of satellite images from 1978 and 2011. The results show a loss of beach and dunes' territory in the Boca Sur neighborhood caused for natural and human factors, as well as possible natural risks to which the park's construction area is exposed due to its localization, relief and dynamics of natural elements. Through microzoning of the park's area, we conclude establishing preferential uses and restrictions to the occupation of the dune field, that from the standpoint of sustainable use are considered relevant for a future intervention.

Keywords: morphodynamics of dunes, coastal area, urban park, natural risk, Chile. 


\section{INTRODUÇÃO}

A Região do Biobío como é conhecida a VIII Região do Chile, localizada entre os paralelos $36^{\circ} \mathrm{e}$ $38^{\circ} 20^{\prime}$ de latitude sul e os meridianos $71^{\circ} \mathrm{e} 73^{\circ} 40^{\prime}$ de longitude oeste, é caracterizada por sua diversidade morfológica por conta da presença da Cordilheira dos Andes, a Depressão Central, a Cordilheira da Costa e a Plataforma Costeira Adjacente (MARDONES, 1986), dando origem a uma grande variedade de climas, solos e ecossistemas que condicionam a ocupação e transformação do território. Os recursos geográficos naturais como os rios, lagos, pântanos, floresta nativa e fauna associada, penínsulas e bacias hidrográficas, abastecem de recursos hídricos e serviços ambientais os principais centros urbanos da região, atuando como elementos estruturantes do desenvolvimento urbano rural da região do Biobío.

A vida econômica, social e cultural da região se organiza e estrutura em torno a estas paisagens e sistemas naturais. A dinâmica regional das atividades produtivas extrativistas, iniciadas com a conquista e colonização, tem provocado importantes transformações territoriais na zona costeira, que ao longo dos anos foram se diversificando, provocando importantes impactos territoriais e ambientais, principalmente pelas praticas florestais. Como conseqüência desse processo histórico de utilização não sustentável dos recursos e espaços naturais, muitos têm sido degradados, substituídos, e em muitos casos total ou parcialmente destruídos (ROJAS et al, 2006). Estes processos econômicos contribuíram a consolidação de assentamentos urbanos na planície costeira, gerando migrações de população rural para estas zonas costeiras produtivas. A região metropolitana de Concepción é um exemplo desse processo.

O deslocamento da população rural para a área metropolitana de Concepción foi incrementado com o terremoto de 1960, onde 18 mil pessoas ficaram sem casa, segundo o Ministerio de Vivendas e Urbanismo do Chile (2010), ocasionando a posse de terrenos perto do centro de Concepción. Com a idéia de erradicar os acampamentos marginais de Concepción, a política do regime militar da década de 1980 transfere estas pessoas a terrenos da planície costeira, dando origem a bairros marginais sem uma planificação adequada para o uso do espaço físico, de equipamentos, de infraestrutura comunitária e de serviços, centrando-se apenas na planificação das vivendas. O bairro Boca Sur, pertencente ao município de San Pedro de La Paz região metropolitana de Concepción, foi criado em 1983 dentro da política de erradicação dos centros urbanos.

A província de Concepción compreende uma dimensão territorial de $3.444,5 \mathrm{Km}^{2}$ com uma população de 1.010.957 de habitantes distribuídos em 10 municípios. Entre os municípios da Grande Concepción está o município de San Pedro de La Paz, que abrange um território de $112,5 \mathrm{Km}^{2}$ onde $19.2 \mathrm{~km}$ são de costa no Oceano Pacífico.

San Pedro de la Paz possui uma população de 80.447 habitantes. O bairro Boca Sur, figura 1, área do presente estudo, localizado na zona costeira do município de São Pedro de La Paz, possui uma área de $13.717 \mathrm{Km}^{2}$ e uma população de 19.062 habitantes, segundo o Censo do ano 2002 (CHILE, 2003). 
Figura 1. Localização geográfica da área de estudo. Elaboração própria
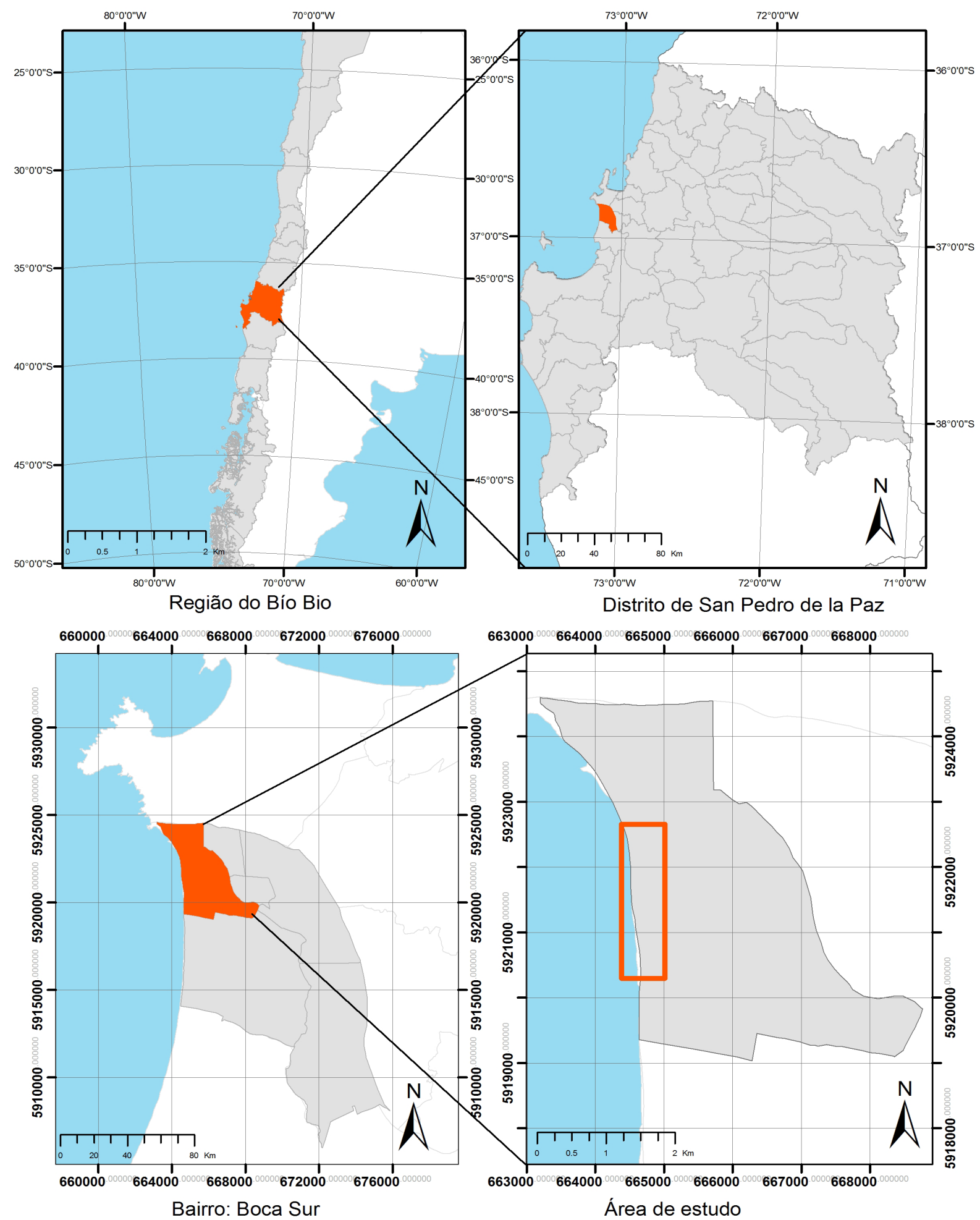

Elaboração dos autores. 
Do ponto de vista da integridade comunitária interna do bairro, segundo estudo realizado pelo MINVU - Ministério de Vivendas e Urbanismo de Chile (CHILE, 2006), Boca Sur corresponde a um "simples agregado humano constituído de indivíduos e famílias localizados em um território, que na sua maioria estão ai por fatores externos a sua vontade própria".

Assim sendo, a promoção de espaços públicos de lazer e recreação foi pensado para reforçar a estrutura organizacional do bairro e a qualidade de vida de seus habitantes. O projeto de construção de um parque urbano no bairro Boca Sur abarcando uma área de um pouco mais de $16 \mathrm{Ha}$ de campo de dunas, foi aprovado pelo Ministério de Vivendas e Urbanismo de Chile para responder os anseios sociais da comunidade local.

Em se tratando de uma área de praia, a construção do parque urbano deve considerar as especificidades e fragilidades da zona litorânea tais como: morfologia das dunas, influencia da dinâmica dos fatores naturais como ventos e marés, os ecossistemas associados e os potenciais riscos naturais que sofre a área de implementação do parque. Dentro dessa perspectiva o presente estudo tem como objetivo apontar alguns critérios de uso e ocupação das dunas na intervenção da área.

\section{MATERIAIS E MÉTODOS}

\section{Classificação morfológica das dunas}

A classificação da morfologia das dunas considerou fatores como: localização, relevo, disposição e grau de colonização vegetal associada à dinâmica de praia, como mostra a Tabela 1 a seguir, que teve como base a classificação apresentada no trabalho de Paskoff e Manríquez, (2004).

Tabela 1. Classificação da morfologia de dunas

\begin{tabular}{|c|c|}
\hline Morfologia das dunas & Elementos de caracterização \\
\hline Paleoduna & Dunas de antiga formação onde atualmente se evidência formação de solo. \\
\hline Duna transversal & Formação bem definida disposta perpendicularmente á direção dos ventos. \\
\hline Duna paralela & Unidade morfológica bem definida paralela à linha de costa. \\
\hline Duna não definida & $\begin{array}{l}\text { Unidade morfológica estabilizada por densas plantações de espécies exóticas, } \\
\text { que não permitem definir corretamente a forma das dunas. }\end{array}$ \\
\hline Duna longitudinal & $\begin{array}{l}\text { Cordões paralelos alongados no sentido dos ventos dominantes, podendo se } \\
\text { estender por centenas de metros separados por corredores pouco profundos. }\end{array}$ \\
\hline $\begin{array}{l}\text { Duna de borde (conjunto de formas } \\
\text { transversal e longitudinal) }\end{array}$ & $\begin{array}{l}\text { Unidade morfológica em formação, caracterizado por apresentar frequência } \\
\text { de pequenos montes isolados com pouca ou nenhuma vegetação do tipo } \\
\text { herbácea. }\end{array}$ \\
\hline Depressão & $\begin{array}{l}\text { Área baixa da topografia onde o lençol freático aflora sazonalmente, permi- } \\
\text { tindo a presença de áreas úmidas. }\end{array}$ \\
\hline Corpos d'água & $\begin{array}{l}\text { Área baixa da topografia onde o lençol freático aflora, permitindo a presença } \\
\text { de água por quase todo o ano. }\end{array}$ \\
\hline Corredor de deflação & $\begin{array}{l}\text { Área de transporte de sedimentos finos pelos ventos, onde não existe barreira } \\
\text { vegetal. }\end{array}$ \\
\hline
\end{tabular}

Fonte: Paskoff e Manríquez (2004). Adaptação dos autores. 
A metodologia utilizada para caracterização da morfologia das dunas consiste basicamente na fotointerpretação de imagens aéreas, observações de campo e na elaboração de perfis topográficos trans- versais da área de implementação do parque. Foram traçados três perfis topográficos dentro de uma área de 16, $15 \mathrm{Ha}$, com auxilio do instrumento GPS Dupla frequência, (figura 2).

Figura 2. Localização do polígono do parque e perfis topográficos.

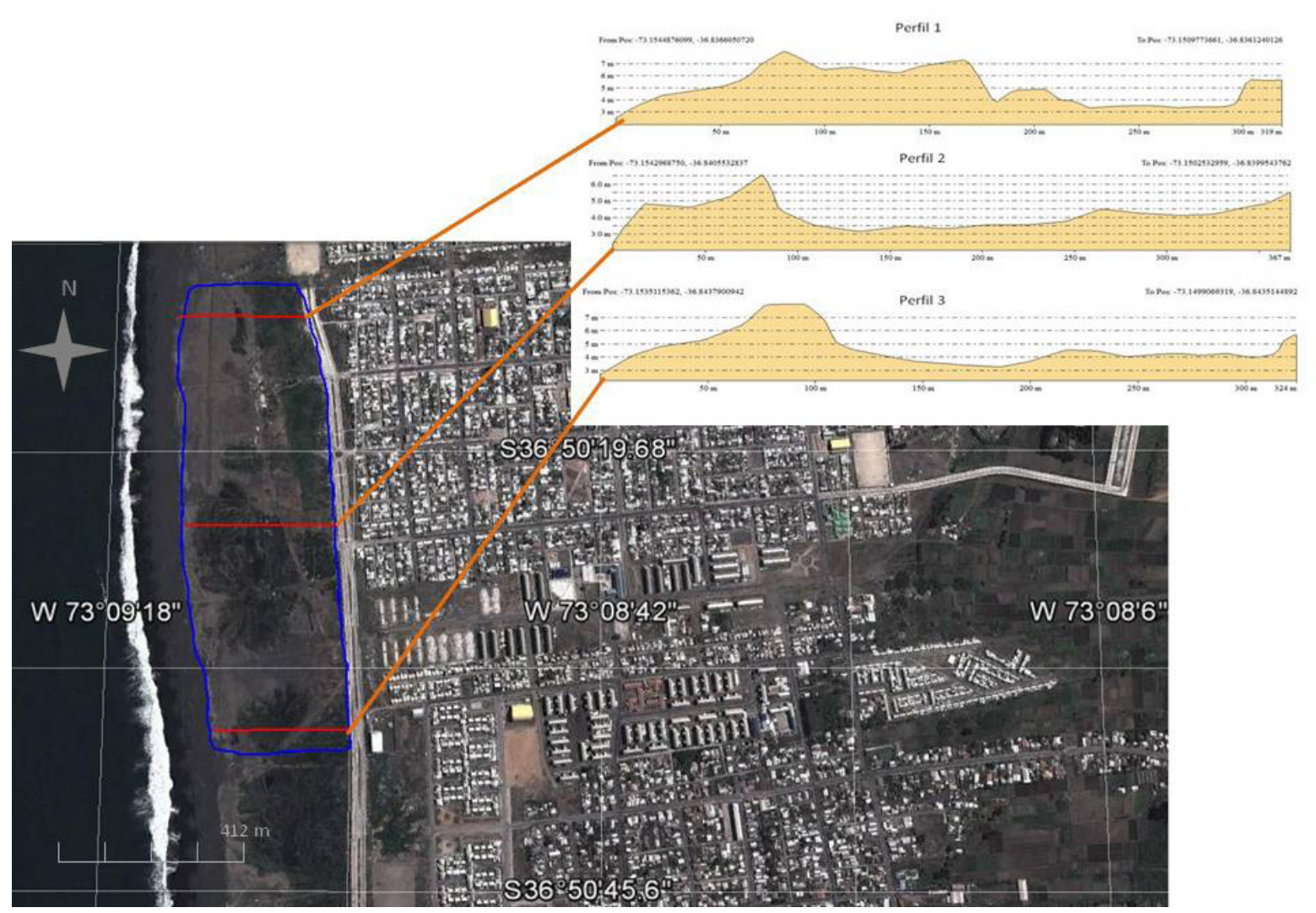

Fonte: Imagem de satélite, adaptação dos autores.

Um estudo dos ventos predominantes no setor foi realizado com o objetivo de verificar a influencia dos ventos na dinâmica das dunas. Esse estudo teve como base os dados da estação metereológica Carrier Sur, disponibilizados pela Direção Metereológica do Chile. A estação Carrier Sur esta localizada no aeroporto da cidade de Concepción, nas coordenadas $36^{\circ} 46^{\prime} 22^{\prime \prime}$ de latitude Sul e $73^{\circ} 3^{\prime} 47^{\prime \prime}$ de longitude Oeste, a uma elevação do nível do mar de $8 \mathrm{~m}$. Esta estação é a mais próxima da área de estudo, cuja localização geográfica é $36^{\circ} 49^{\prime} 56^{\prime \prime}$ latitude S e $73^{\circ} 06^{\prime} 56^{\prime}$ " longitude $\mathrm{O}$.

Foram realizadas também, análises da precipitação no setor considerando os períodos de estiagem (setembro a março) e os períodos chuvosos (abril a agosto) dos últimos 5 anos, entre os anos de 2005 e
2010. O objetivo foi de averiguar a relação dos níveis de precipitação dos diferentes períodos do ano na dinâmica que sofre os sedimentos principalmente no cordão frontal das dunas.

\section{Grau de Estabilização das Dunas}

O grau de estabilização das dunas foi avaliado mediante a quantificação da cobertura vegetal com base nas observações de terreno e na fotointerpretação de imagens de satélites. Os critérios utilizados para definir o grau de estabilização das dunas, foram definidos por Peña Cortes et al., (2008) que estabelecem quatro graus de estabilização de dunas, apresentados na Tabela 2, definidos como: dunas ativas, dunas parcialmente estabilizadas, dunas estabilizadas e dunas antigas. 
Tabela 2. Grau de estabilização das dunas

\begin{tabular}{|l|l|}
\hline Dunas Ativas & $\begin{array}{l}\text { Cobertura vegetal menor que 30\% com espécies } \\
\text { herbáceas }\end{array}$ \\
\hline Dunas Parcialmente Estabilizadas & $\begin{array}{l}\text { Vegetação mista de espécies herbáceas e/ou arbustivas } \\
\text { com cobertura entre } 20 \% \text { e } 60 \%\end{array}$ \\
\hline Dunas Estabilizadas & $\begin{array}{l}\text { Vegetação mista de espécies herbáceas e/ou arbustivas } \\
\text { com cobertura maior que } 60 \%\end{array}$ \\
\hline Dunas Antigas & $\begin{array}{l}\text { Vegetação sobre solo em desenvolvimento (pradaria- } \\
\text {-arbustiva) }\end{array}$ \\
\hline
\end{tabular}

Fonte: Peña Cortes et al, 2008.

\section{Evolução e desenvolvimento da ocupação dos cam- pos de dunas}

Para a análise das mudanças dos usos do território de dunas, foram elaborados mapas do uso do solo com base na fotointerpretação de imagens aéreas e de satélites dos anos de 1978 e 2011, utilizando como base de informação o plano regulador do município de San Pedro de La Paz, além das visitas de campo e coleta de dados. Esta análise foi efetuada a nível do bairro Boca Sur, e se baseou na comparação da variação dos usos da superfície territorial de 1978, antes do assentamento do bairro Boca Sur, em relação aos usos atuais, dando ênfase ao terreno de dunas.

\section{RESULTADOS E DISCUSSÃO}

\section{Processo de formação das dunas litorâneas}

A morfogênese da planície arenosa da área que vai desde San Pedro de la Paz até a cidade de Coronel (36 $\left.46^{\circ} \mathrm{S}-37^{\circ} 01^{\prime} \mathrm{S}\right)$ na área litorânea da região do Biobío, tem sua origem no período Pleistoceno Superior Recente, quando os primeiros sedimentos foram depositados pelo mar ao pé da Cordilheira de La Costa. Posteriormente, no período Holoceno, o mar sofreu regressão transformando essa planície em uma área baixa e pantanosa, que recebia uma grande carga de sedimentos trazidos e depositados por rios e cursos d'água que deram origem ao grande delta de Concepción - Talcahuano (cidade conurbada). Esse processo obstruiu as águas continentais vinda dos vales das cordilheiras com a formação de barreiras arenosas, que deram origem a terraços marinhos, originando também a formação de algumas lagoas na região. As variações de nível oceânico, transgressões e regressões, ocorridas no período Holocénico deram origem aos cordões marinhos, que segundo Paskoff, (1970), podem ter idade entre 4000 a 2000 anos, de acordo com seus estudos na zona litorânea do Chile. Esses cordões marinhos, podem ser vistos desde o pé da Cordilheira de La Costa seguindo por toda a extensão da planície arenosa até a altura onde hoje esta localizada as dunas antigas da praia do bairro Boca Sur. A formação da praia e das dunas atuais pode ser entendida pela dinâmica dos sedimentos que são transportados pelos rios e cursos d'água continentais até a desembocadura do rio no oceano, que por sua vez são devolvidos ao litoral pela ação das marés associada com a dinâmica e a força dos ventos predominantes da área, S e SW, e depositados na linha de costa dando origem a praia e as dunas atuais da área de estudo.

As principais condições naturais que possibilitam a formação de dunas no Chile estão relacionadas com a grande quantidade de areia disponível nas praias, clima com pelo menos um período seco anual, que possibilita a deflação eólica, orientação favorável à linha de costa em relação aos ventos predominantes e um espaço topográfico propenso à formação de dunas (CASTOR, 1985).

A área estudada reúne com todas as condições de formação de dunas, considerando que sua linha costeira é reta de praia arenosa ocorrendo processos ativos de erosão nas temporadas de inverno e de 
acréscimo nas temporadas de verão. No verão o clima é seco entre os meses de fevereiro a março, que associado com a maré baixa expõe as areias à ação dos ventos que transportam os sedimentos para o interior do continente dando origem à formação de dunas.

Segundo sua localização, as dunas do bairro Boca Sur podem ser classificadas de litorâneas ou costeiras, constituídas de sedimentos de origem marinha e fluvial. Os sedimentos fluviais são removidos da desembocadura do rio Biobío, localizada na parte norte da praia (figura ${ }^{\circ} 6$ ), pela ação das marés e se estendem ao longo da costa (GORMAZ, 1974). Segundo seu relevo, o cordão frontal das dunas foi classificado como dunas em forma de arco que apresenta como característica uma inclinação suave a barlavento, enquanto que a sotavento apresenta uma abrupta caída, na qual estabelece uma ruptura de pendente absoluta de ordem de $80^{\circ}$ a $85^{\circ}$ (BORGEL, 1963). Tais características podem ser observadas na Figura 3, que mostra o perfil transversal 3 das dunas de Boca Sur.

Figura 3. Perfil de dunas de arco.

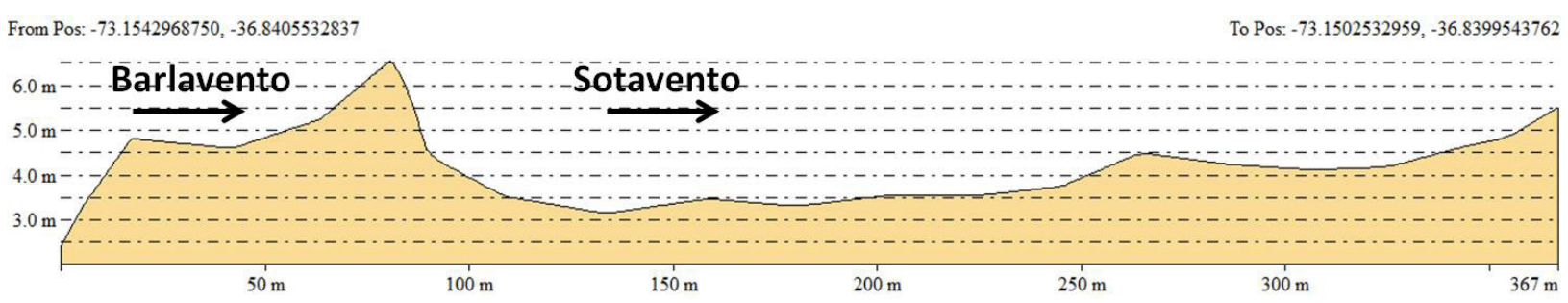

Elaboração dos autores.

Segundo sua disposição as dunas da planície costeira ao sul do rio Biobío são do tipo transversal. Paskoff e Martines (2004), descrevem esse tipo de dunas como de formação bem definida com um cordão alargado paralelo à praia e transversal à direção dos ventos de acresção. Na área de estudo os ventos predominantes ocorrem de $\mathrm{S}$ a SE, e a pouca precipitação durante o verão faz com que as dunas transversais alcancem um desenvolvimento pleno de suas formas.

O estudo da morfodinâmica de praia considera variáveis físicas como: inclinação da praia, clima, grau de exposição a marés e origem dos seus sedimentos.
Dependendo dessas variáveis as praias podem ser classificadas em: dissipativas, refletivas e intermediárias. De acordo com as observações de campo, a praia de estudo foi classificada como uma praia fortemente refletiva, caracterizada pelas ondas de alta energia de mais de $1 \mathrm{~m}$ de altura, rompendo diretamente na areia da praia e com ocorrência de dissipação de energia em uma zona muito próxima á linha de praia. Esta condição é típica de praias refletivas, que se caracterizam por apresentarem uma grande pendente (SHORT, 1996; ANFUSO et. al., 2001). O perfil 2 ilustrado na figura 4, mostra as características descritas acima para praia refletiva.

Figura 4. Inclinação intertidal da área de estudo.

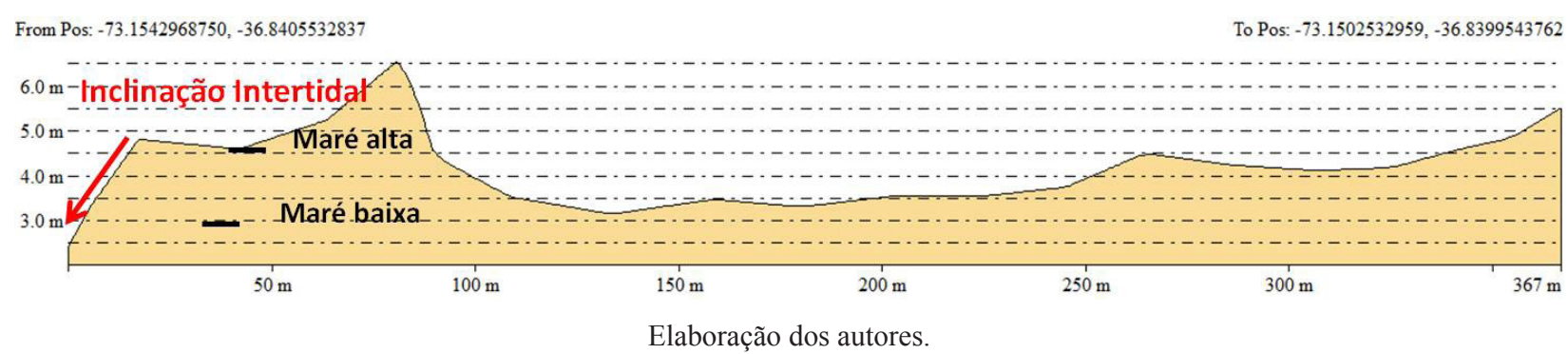


Em relação ao transporte de sedimentos com base nas considerações apresentadas, a praia refletiva por possuir inclinação acentuada, estabelece entre os limites extremos de alta e baixa maré uma pequena superfície de exposição subaérea, ou seja, a carga de material exposta ao vento é pequena comparada com praias de pendente menos inclinada.

O transporte eólico estabelece uma pequena relação entre o tamanho do sedimento (granulometria), velocidade e capacidade de suspensão (arrasto) dos sedimentos, essa capacidade esta associada com a intensidade dos ventos. Os ventos mais intensos são os que determinam o desenvolvimento crescente das dunas para o interior da planície e oscilam em relação ao transporte das partículas de acordo com o diâmetro do sedimento (BORGEL, 1963).

Os ventos predominantes na área estudada nos meses de chuva são de direção $\mathrm{N}$, com uma intensidade que varia entre 9,8 nós $(16,6 \mathrm{~km} / \mathrm{h})$ e 6,6 $(11 \mathrm{Km} / \mathrm{h})$, porém, já foram registrados pelo serviço meteorológico do Chile alguns eventos extremos de fortes ventos na área, atingindo uma velocidade de até $130 \mathrm{Km} / \mathrm{h}$. Vale destacar que os ventos do quadrante norte associados ao período chuvoso (Tabela 2), não provocam o transporte de areias por ação eólica, considerando que a areia molhada tem seus grãos agregados e, portanto, são muito densos para mobilização pelo transporte eólico. A remoção dos sedimentos neste período ocorre pela ação da maré alta e de eventos como ressaca do mar, que são comuns nesse período.

Os ventos predominantes no período de estiagem são do quadrante $S$, atingem uma velocidade media de 10,2 nós. Estes ventos associados ao período seco e de intensa radiação solar, são chamados de ventos de acresção. Tais ventos levam este nome porque transportam os sedimentos sem umidade e expostos à zona intertidal, condições favoráveis para o transporte eólico de areias. As areias da praia do bairro Boca Sur, são classificadas conforme sua granulometría de media a fina com tonalidade cinza pardo. Grande parte dos sedimentos transportados pela ação eólica são acumulados no cordão frontal de dunas adentrando o interior da planície.

\section{Grau de Estabilização das Dunas}

As dunas costeiras, em um sentido mais biológico, são caracterizadas por um processo psamoseral entendido como uma sucessão vegetacional, ocorrendo a formação de um ecossistema que eventualmente chega a um equilíbrio, segundo Walter (1968). A linha costeira se apresenta em um primeiro plano de sucessão, que segue com o cordão frontal de dunas, ou dunas primarias que constitui o inicio da psamosere, seguindo a sucessão ao longo do interior da planície para as dunas secundárias e por ultimo as dunas terciárias ou paleo dunas (figura 5). 
Figura 5. Perfil topográfico transversal das dunas Boca Sur.

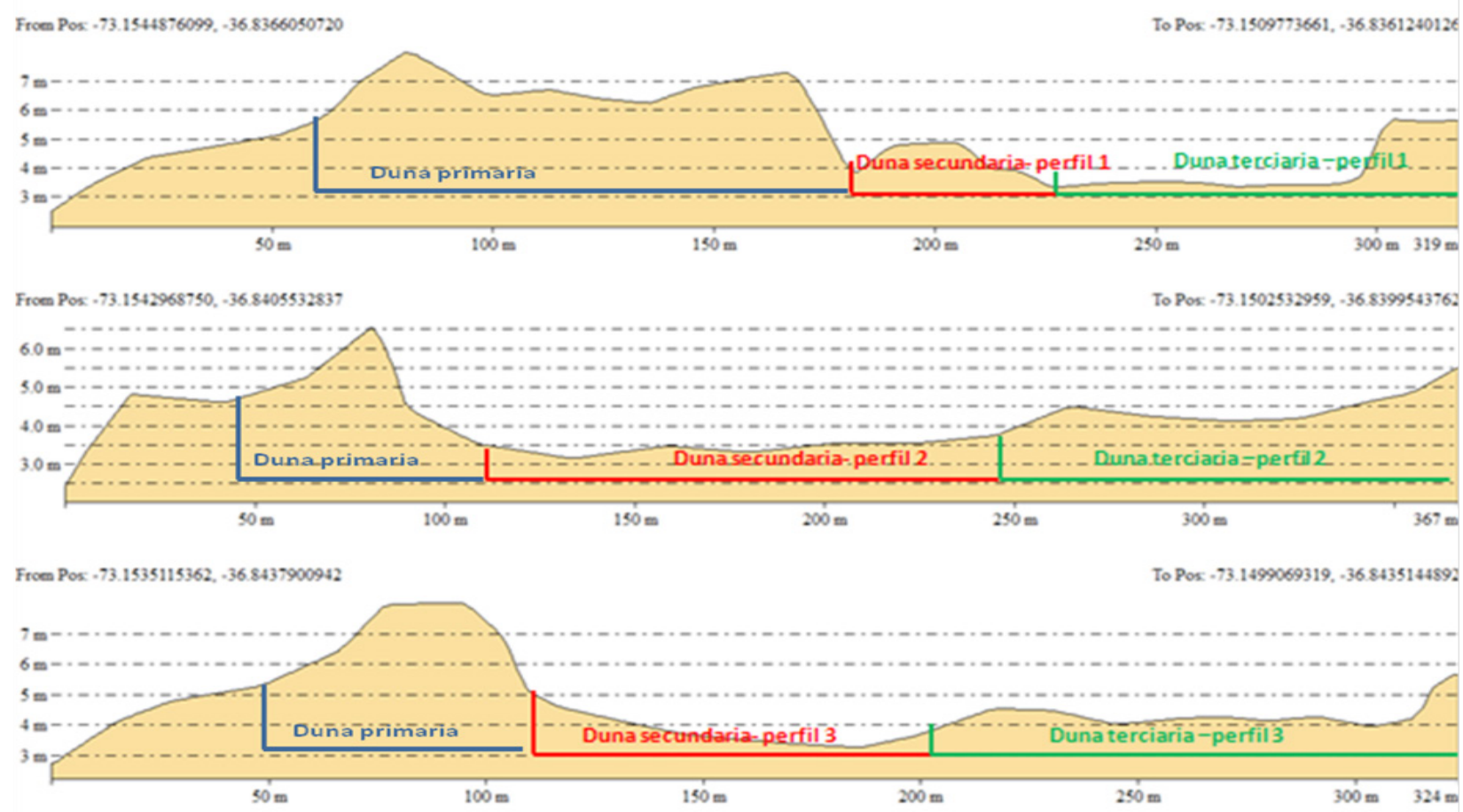

Elaboração dos autores.

A praia do bairro Boca Sur por estar localizada ao sul da desembocadura do rio Biobío, sofre com os efeitos perturbadores do rio, com a exposição à maré alta e com as eventuais ressacas que ocorrem nas temporadas de inverno, o que dificulta a estabilização da cobertura vegetal no cordão frontal de dunas. Alem dos fatores naturais, a constante intervenção nas dunas por ações antrópicas registradas na área de estudo, tais como: a extração irregular de areia, entrada de veículos e pisoteio de pessoas e animais, são fatores que dificultam a fixação e desenvolvimento da cobertura vegetal principalmente na faixa que corresponde às dunas primárias.

As dunas primarias foram classificadas como dunas ativas, ou seja, com um grau de até $30 \%$ de cobertura vegetal. A vegetação é composta por psammophila, principalmente de gramíneas resistentes á salinidade e porosidade do solo arenoso, distribuídos espaçadamente e com baixa cobertura, o que facilita a dinâmica de remoção e deposição de areias ocorrendo de forma estacional durante o ano.

As dunas secundárias em geral ocupam uma maior superfície que a primeira e um maior grau de estabilização. Foi observado que o grau de evolução dos solos aumenta em matéria orgânica e umidade à medida que vai adentrando a planície costeira. A presença do lençol na superfície se torna visível em vários pontos, formando pequenas lagunas nos períodos de chuva. Associadas às condições topográficas do relevo de depressão, as dunas secundarias são protegidas pelas dunas primarias contra a ação erosiva do mar e dos ventos, gerando condições adequadas para o desenvolvimento de uma biomassa vegetal diversificada. As dunas secundarias foram classificadas como dunas estabilizadas, ou seja, com um grau de cobertura vegetal superior a $70 \%$ da sua área. A vegetação é do tipo herbáceo e com arbustos, predominando as especies juncáceas e gramíneas.

A duna terciária, como última etapa da psamosere, apresenta uma maior estabilidade em nível de substrato e uma maior quantidade de matéria orgânica. Segundo Ramírez et al., (1992) é a mais manuseada no Chile Central para o reflorestamento com espécies exóticas do tipo arbustivas e arbóreas. $\mathrm{Na}$ zona de 
estudo isso não é diferente, já que foram observadas algumas áreas de reflorestamento com pinus radiata.

As dunas terciárias foram classificadas como paleo dunas ou dunas antigas com presença de uma pradaria natural sobre solos desenvolvidos, formando um habitat natural para as aves terrestres e aquáticas presentes na região. Esta área também é utilizada para pastagem de animais, como observado em campo.

Parte desta área de dunas antigas foi urbanizada com instalações industriais, residenciais e com estradas pavimentadas. Além disso, a degradação dessa área de dunas, é incrementada pela ação dos moradores do bairro que utilizam este espaço como deposito e queima de lixo, despejo de resíduos de construção civil e para extração de areias.

\section{Evolução e desenvolvimento da ocupação das dunas nos últimos 30 anos}

Foram elaborados mapas de uso do solo para os anos de 1978 e 2011 (Figura 6), com o objetivo de realizar a analise das mudanças do uso do solo nesse intervalo de tempo. A matriz comparativa, apresentada na Tabela 3, mostra os resultados da sobreposição dos planos dos diferentes usos do solo para os dois anos analisados no presente estudo.

Figura 6. Usos do solo bairro Boca Sur, anos de 1978 e 2011 respectivamente.
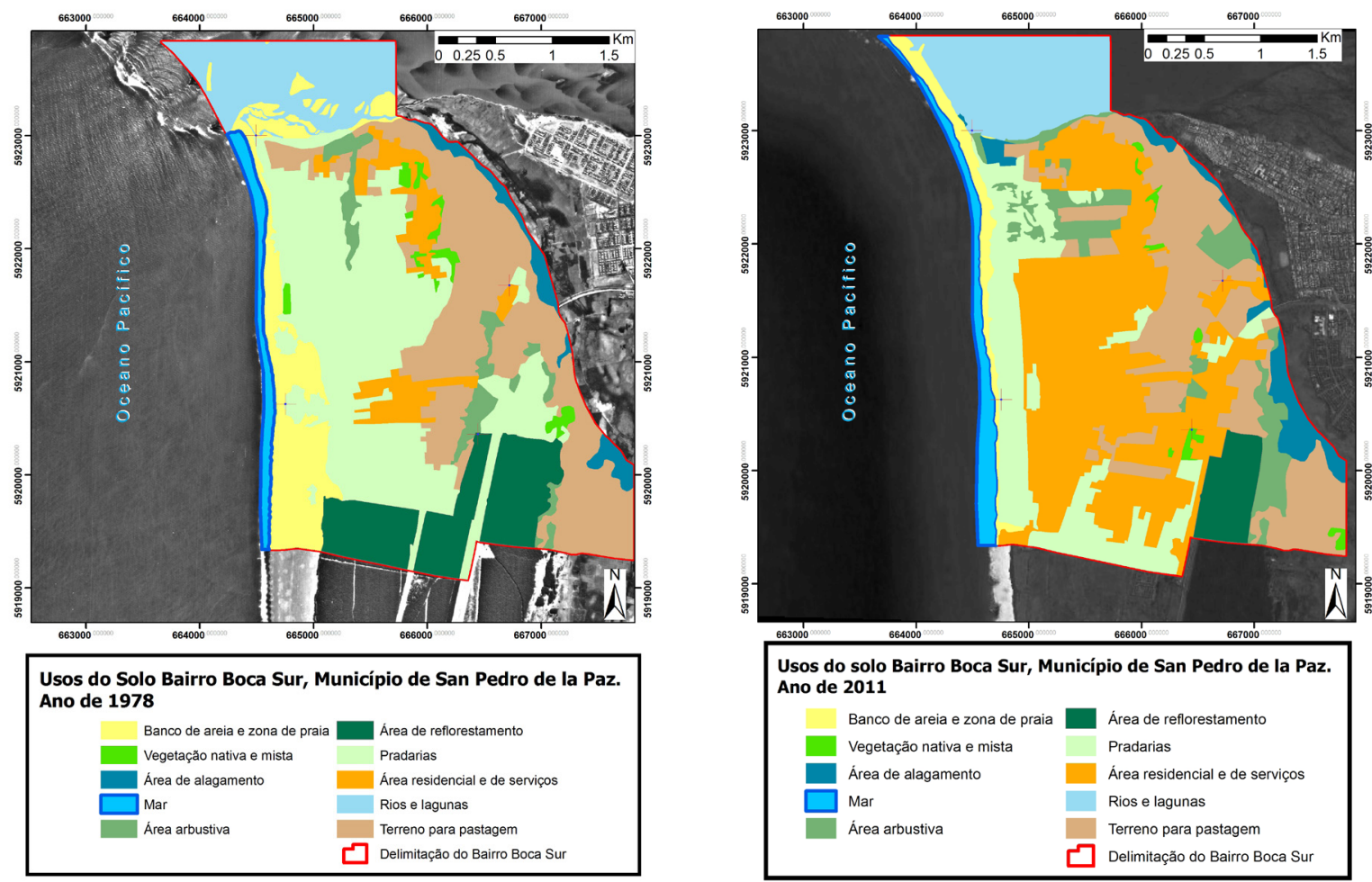

Elaboração dos autores.

De acordo com os resultados obtidos com a sobreposição dos mapas, foi possível identificar as mudanças na superfície $\left(\mathrm{m}^{2} \mathrm{e} \%\right)$, tanto negativas como as positivas, ocorridas entre os anos de 1978 e 2011, explicitadas na Tabela 3. 
Tabela 3. Matriz comparativa dos usos do solo para os anos de 1978 e 2011.

\begin{tabular}{|l|c|c|c|c|c|}
\hline \multicolumn{1}{|c|}{ Usos do solo } & \multicolumn{2}{|c|}{ Superfícies m } & \multicolumn{2}{c|}{ Superfícies \% } & $\begin{array}{c}\text { Mudanças\% } \\
\text { (negativas e positivas) }\end{array}$ \\
\hline & 1978 & 2011 & 1978 & 2011 & $1978-2011$ \\
\hline Mar & 308005 & 480661 & 2.6 & 4.1 & 1.5 \\
\hline Bancos de areia e praia & 1204463 & 333713 & 10.4 & 2.9 & $-7,5 \%$ \\
\hline Vegetação nativa e mista & 147723 & 83475 & 1.3 & 0.7 & $-0,6$ \\
\hline Zonas baixas e úmidas & 257790 & 402222 & 2.2 & 3.5 & 1.3 \\
\hline Vegetação arbustiva & 380876 & 794814 & 3.3 & 6.8 & 3.5 \\
\hline Área de reflorestamento & 1278526 & 423493 & 11.0 & 3.6 & -7.4 \\
\hline Praderas naturais & 3528230 & 1723273 & 30.3 & 14.8 & -15.5 \\
\hline Residencial e de serviços & 640053 & 3832875 & 5.5 & 32.9 & 27.4 \\
\hline Rios e lagunas & 1132279 & 1237646 & 9.7 & 10.6 & 0.9 \\
\hline Terrenos agropecuários & 2758608 & 2324381 & 23.7 & 20.0 & -3.7 \\
\hline Total geral & 11636554 & 11636554 & 100.0 & 100.0 & \\
\hline
\end{tabular}

Org. dos autores.

Da leitura dos dados se podem destacar os seguintes aspectos: o campo de dunas e a zona de praia ao longo da costa perderam em superfície mais de 870.000 $\mathrm{m}^{2}$ nos últimos 30 anos. Esta área tinha em 1978 um total de $1.204 .463 \mathrm{~m}^{2}$ que representava $10.4 \%$ da área total do bairro, atualmente a área de praia e dunas representa somente $2,9 \%$ do território total do bairro boca Sur.

As dunas do bairro Boca sur já atingiram uma altura máxima de $18 \mathrm{~m}$. Atualmente as dunas mais altas chegam a ter um pouco mais de 7 metros de altura, como mostra a figura 5 apresentada anteriormente. Esta extensão de areia ao longo dos anos sofreu mudanças significantes na sua morfologia principalmente pela ação antrópica. Fatores como: a crescente urbanização no setor, construção de vias pavimentadas, indústria e o aumento da área residencial são os principais fatores responsáveis pelas mudanças na cobertura da superfície de praia, dunas e pradera natural.

A perda de superfície de praia e dunas ocorreu devido a fatores natural e antrópico. Foi identificado como fator natural o aumento do nível do mar nos últimos 33 anos e como fatores antrópicos além da urbanização da área, a retirada de areia das dunas para construção civil e a destruição da vegetação fixadora de dunas pelo pisoteio de pessoas, animais e trafico de automóveis sobre o campo de dunas. Pode-se observar também, que o mar cobriu boa parte da praia e dunas no setor sul, tomando um pouco mais de $17.000 \mathrm{~m}^{2}$ do território de dunas, em média de $5.151 \mathrm{~m}^{2}$ por ano num intervalo de tempo de 33 anos. Os resultados da análise mostram uma significativa dinâmica marinha neste setor, que deve ser considerada para qualquer futura intervenção na área.

A análise das imagens de satélite, mostra que houve uma variação na dinâmica de deposição de sedimentos na extensão total da área em análise, ou seja, há um aumento em extensão de praia e dunas sobre a pradera natural na parte norte da praia, ao sul da desembocadura do rio Biobío. Grande parte dos sedimentos da área de estudo são atribuídos a carga aluvial abundante de origem vulcânica, transportada pelo fluxo do rio desde a nascente do rio Biobío, localizada a uma altitude de 1160 m.s.n.m na Cordilheira dos Andes, até a sua desembocadura no Oceano Pacífico, onde se forma um estuário. Observou-se na comparação das imagens de satélite (Figura 6), para o ano de 2011, um acúmulo de sedimentos na desembocadura 
do rio, aumentando em extensão o cordão arenoso que separa o rio do mar na parte ao norte da praia. Essa ocorrência pode ter como fatores responsáveis a dinâmica sazonal da vazão do rio, que no período chuvoso entre os meses de junho e julho atinge uma média mensal de $2.200 \mathrm{~m}^{3} / \mathrm{s}$, e nos períodos de seca entre os meses de março e abril essa vazão varia de180 $\mathrm{m}^{3} / \mathrm{s}$ a $220 \mathrm{~m}^{3} / \mathrm{s}$. Outro fator a ser considerado são as construções de duas centrais hidrelétricas no alto curso do rio Biobío, sendo que a primeira delas começou a operar no ano de 1996 e a segunda em 2003. Segundo Valdovinos e Parra (2006), essa intervenção no curso natural do rio, modifica o fluxo continuo da vazão até o delta do rio na desembocadura, alterando, entre outros fatores, o acumulo de depósito de sedimentos.

A análise da área circundante á área de dunas revela que houve substituição de terreno agropecuário e de pradera natural por área residencial. Em 1978 existia um total de um pouco mais de $640.000 \mathrm{~m}^{2}$ de área construída equivalente a $5 \%$ de área total do bairro para quase $4.000 .000 \mathrm{~m}^{2}$ de área construída em 2011, ou seja, mais de 30\% da área total do bairro está urbanizada.

Os dados para o ano de 1978 mostram que os usos do solo predominantes, estão associados a atividades agrícolas, atividades florestais, plantações e cobertura de mata nativa e mista. Vale ressaltar também, que muitos dos terrenos de praderas da época foram originados por antigos terrenos agrícolas que perderam sua capacidade de produtividade.

A intensa atividade florestal em 1978 pode ser explicada pelo processo de abertura da economia do Chile aos mercados internacionais, em meados de 70 , que fomenta e subsidia novas atividades econômicas, como foi o caso da atividade florestal.

\section{Riscos Naturais da área de Estudo}

São Pedro de La Paz é o segundo município, da área metropolitana de Concepción (AMC), depois de Talcahuano, que apresenta maior vulnerabilidade frente às ocorrências de catástrofes naturais. $\mathrm{O}$ município possui uma superfície total de 11.250 há, dos quais 6.705 há apresentam algum tipo de risco natural, equivalente a $59,6 \%$ do território total do município. A tabela 4 apresenta a tipologia dos riscos naturais apresentados para o setor da área de estudo.

Tabela 4. Tipologia dos riscos naturais San Pedro de La Paz.

\begin{tabular}{|l|c|c|}
\hline \multicolumn{3}{|c|}{ San Pedro de la Paz } \\
\hline Tipo de Riscos & Superficie em (ha) & Superficie em \% \\
\hline Tsunami & 512 & 0,77 \\
\hline Alagamento & 584 & 0,88 \\
\hline Inundação fluvial & 210 & 0,31 \\
\hline Inundação marinha & 364 & 0,55 \\
\hline Deslizamento de massa & 4.356 & 6,61 \\
\hline Deflação eólica & 679 & 1,03 \\
\hline
\end{tabular}

Fonte: Mardone e Vidal (2001).

A faixa litorânea do bairro Boca Sur, está entre as zonas de maior risco de inundação em caso de tsunami e ressaca do mar, junto com o município de Penco e a ilha de Rocuant em Talcahuano.

Importante destacar que o risco de deflação eólica na área de estudo, tende a evoluir em seus processos dinâmicos para o interior da planície, podendo atingir a área residencial. Fatores como a expansão urbana na faixa costeira e a degradação dos ambientes naturais costeiros, aumentam a exposição das pesso- as que vivem nessas áreas, aos riscos naturais. Em geral as áreas mais vulneráveis aos eventos naturais extremos, são de pouco valor imobiliário, portanto, ocupadas pela população de baixa renda.

Assim sendo, se deve considerar medidas que podem amortizar os efeitos dos possíveis eventos naturais extremos. A proteção e recuperação dos cordões frontais de dunas, como medida de proteção contra ressacas e contenção da deflação eólica, devem ser considerados na intervenção da área para cons- 
trução do parque. A degradação dos diversos tipos de vegetação ao longo de muitas zonas costeiras tem aumentado sua vulnerabilidade frente aos eventos naturais extremos como ressacas e tsunamis. A criação de barreiras naturais, como os bosques de proteção na zona de praia, pode fazer grandes diferenças na redução dos efeitos de futuros fenômenos naturais extremos (CHILE, 2000).

\section{CONCLUSÃO: CRITÉRIOS DE USO E OCU- PAÇÃO DAS DUNAS NA CONSTRUÇÃO DO PARQUE URBANO}

O uso do parque na área de dunas está permitido no Plano Regulador Comunal de São Pedro de la Paz. Para concretizar-lo, o Serviço de Vivendas e Urbanização (SERVIU), dependente do Ministério de Vivendas e Urbanismo (MINVU), contratou uma consultoria que teve entre seus objetivos gerais "Estabelecer critérios de ocupação do solo, através de microzonificação do campo de dunas, considerando variáveis ambientais, sociais e urbanísticas".

Os critérios de uso e ocupação das dunas foram estabelecidos em resposta aos objetivos específicos de: "Realizar zonificação e/ou microzonificação da área de estudo, em função das conclusões do diagnóstico ambiental interpretativo, estabelecer usos preferentes e restrições para ocupação das dunas"; "Realizar proposta de critérios de ocupação e uso do campo de dunas".

A criação do bosque de proteção mencionada para a área de dunas primaria, seria um primeiro critério de ocupação, que admite áreas menores de recreação tais como zonas de pic-nic e trilhas. Com a mesma priorização recomenda-se a recuperação da vegetação fixadora de dunas, que atualmente possui
$30 \%$ da cobertura vegetal, no cordão frontal das dunas primarias.

Como segundo critério de ocupação, e pela necessidade de deslocamento interno próprio de um parque, recomenda-se que o desenho dos caminhos internos ao parque, respeite a morfologia das dunas, ou seja, que circundem o cordão frontal delimitando-o e ao mesmo tempo protegendo-o. Em todo caso, sugere-se que essa circulação seja exclusivamente para pedestres.

Como critério geral de acessibilidade, recomenda-se um maximo de três acessos ao parque onde apenas um seja para o acesso de veículos, idealmente materializados com pavimentos drenantes, cujo traçado pode ocupar o cordão dunario terciário sem maiores problemas, parcialmente o secundário e não recomendado para o cordão primário para este fim. As zonas de estacionamento geral devem ser colocadas adjacentes a avenida existente, paralela a linha de costa e anterior a área de dunas, limitando a entrada desnecessária de veículos nas áreas de dunas.

Para a área das dunas secundarias, no entanto, se recomenda a implantação de estruturas leves como mirantes e passarelas em palafita que permita o deslocamento dos visitantes e também a conservação da vegetação fixadora de dunas, vinculando funcionalmente as áreas de dunas e possibilitando a apreciação do parque e a contemplação da paisagem natural do lugar.

Por último, se recomenda interferir o mínimo possível nas pequenas áreas úmidas existentes em meio à vegetação das dunas secundaria e terciária. A incorporação de arbustos ou setas indicando a existência de "área úmida" pode ser parte da área paisagística e usos recreativos do futuro parque, figura 7 . 
Figura 7. Microzonificação da área de estudo com usos preferentes e restrições.
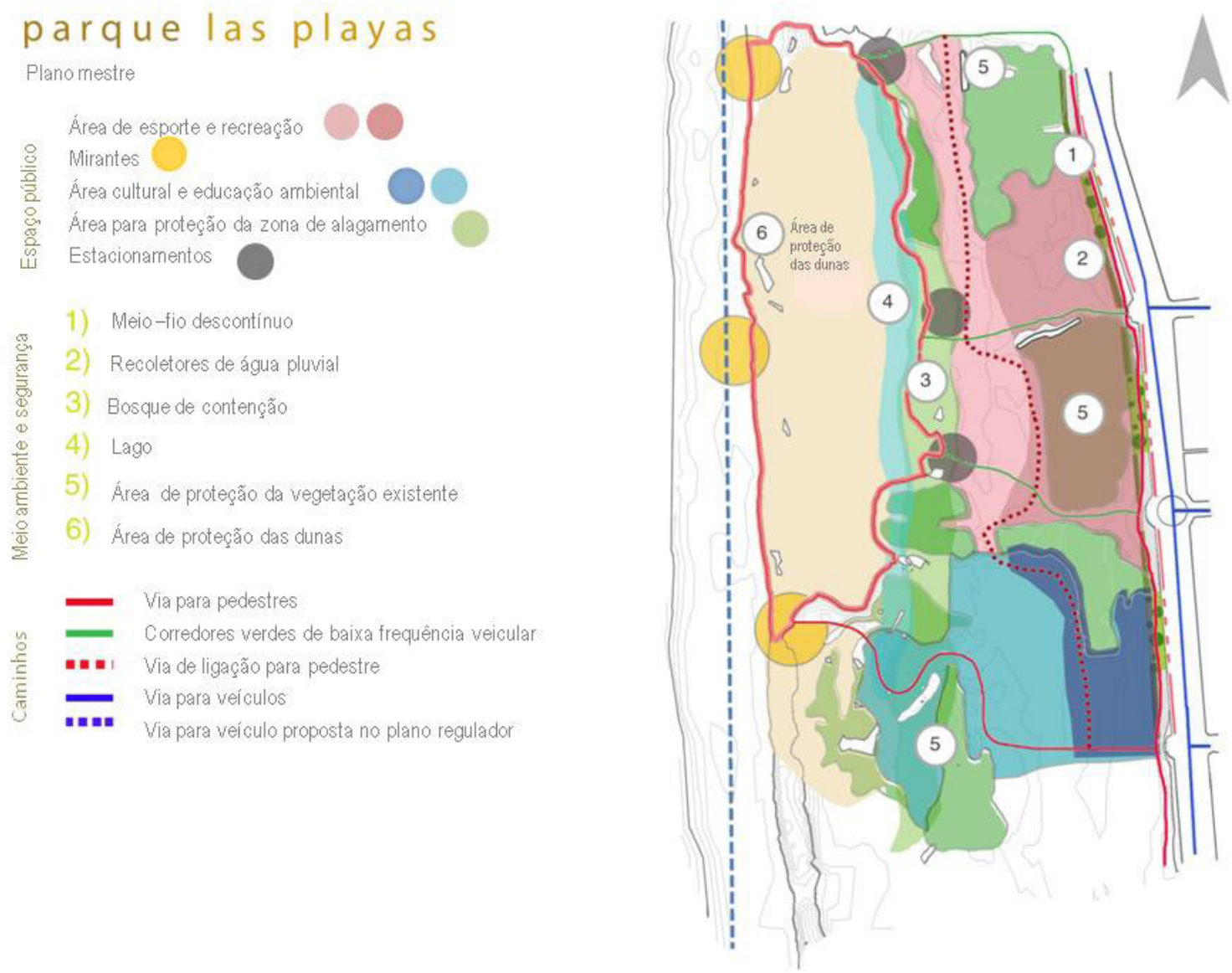

Elaboração dos autores.

\section{AGRADECIMENTOS}

Os autores agradecem o apoio do CONICYT/ FONDAP 15110020, Centro de Desarrollo Urbano Sustentable (CEDEUS) do Chile.

\section{REFERÊNCIAS}

ANFUSO, G.; BENAVENTE, J.\& GRACIA, F.J. Morphodynamic response of nourished beaches in $S W$ Spain. 7 ed. USA. Journal of Coastal Conservation. 2001. p. 71-80.

BORGEL, O. R. Las Dunas Litorales de Chile. Teoría y Aplicación. 3 ed. Santiago. Universidade do Chile, Faculdade de Filosofia e Educação. 1963. p. 5-15.
CASTRO C. Reseña del Estado Actual del Conocimiento de las Dunas Litorales en Chile.. Terra Australis. Revista Geográfica de Chile. N.1, p 13-32. 1985.

CHILE (Corporación Nacional Forestal). Bosque nativo chileno. Un recurso para el desarrollo. Santiago do Chile, 2000.

CHILE (Ministério de Vivenda e Urbanismo do Chi1e). Estudio diagnostico técnico de base barrio Boca Sur comuna de San Pedro de la Paz. Habiterra. 2006.

CHILE (Instituto Nacional de Estadística, INE). Censo 2002. Síntese de Resultados. Santiago do Chile. 2003

GORMAZ, G. M. Las Dunas. Santiago. Corporación Nacional Forestal (CONAF). 1974. p.17-62. 
MARDONES, M. Sistemas Naturales Integrados de la Región del Bíobío. Terra Australis. Revista geográfica de Chile. 1986. p. 49-60.

MARDONES, M. et al. Geografia de Chile. Región del BÍO BÍO. Santiago. Instituto geográfico militar. 2001.p. 531.

PASKOFF R. Le Chili semi-aride, recherches géomorphologiques. Bordeaux. Ed. Biscaye. 1970. p. 420.

PASKOFF R. e MANRÍQUEZ H. Las Dunas de la Costa Chilena. Santiago do Chile. Instituto Geográfico Militar. 2004.

PEÑA CORTES, et al. Morfología y dinámica dunaria en el borde costero de la Región de La Araucanía en Chile. Antecedentes para la conservación y gestión territorial. Revista de Geografía Norte Grande. Santiago. N.41, p. 63-80. 2008. DOI: http://dx.doi.org/10.4067/ S0718-34022008000300004

RAMIREZ, C. La Flora de las Dunas Chilenas y sus Adaptaciones Morfológicas. Chile. 1992.

ROJAS, J. et al. Atlas Social y Ambiental Del Área Metropolitana de Concepción, Región del Bio Bio, Chile. Transformaciones sociodemograficas y ambientales. Concepción, 2006.

SHORT, A. The role of wave heigth, period, slope, tide range and embaymentisation in beach clasifications: a review. Revista chilena de historia natural. N.69, p. 589-604.1996.

VALDOVINOS C. e PARRA O. La cuenca Del rio Biobio. Historia natural de uso multiple. Chile. Centro de ciencias ambientales - EULA, Universidade de Concepción. 2006

WALTER, H. Die Vegetation der Erde in ökophysiologischer Betrachtung. Die gemässigten und arktischen Zonen. Vol. 2. Sttutgart: Gustav Fischer,1968. 